\title{
Review
}

\section{Perspectives on Intelligent Road Lighting Control}

\author{
Sanaz BOZORG*,**,† and John D. BULLOUGH***,**** \\ * Aalto University, Department of Built Environment, Finland \\ ** Cambridgeshire County Council, Huntingdon, United Kingdom \\ *** Lighting Research Center, Rensselaer Polytechnic Institute, United States of America \\ **** Light and Health Research Center, Icahn School of Medicine at Mount Sinai, United States of America
}

Received September 9, 2020, Accepted August 30, 2021

\begin{abstract}
Road lighting is best known to have the potential to improve night-time safety. The vast majority of research studies have shown that the installation of road lighting has favourable effects on the number and severity of road collisions. In addition, some evidence suggests that current road lighting practices are over-lighting the roadway. Therefore, the rapidly growing concerns about energy consumption and its related costs will force further changes in road lighting technology and practice. To date, there have been no studies that investigated the association between current knowledge and the road lighting guidelines. This article reviews and discusses CIE road lighting guidelines for motorised traffic. It then provides current knowledge in the area of lighting motorised roads leading to possibilities for intelligent lighting control. Finally, suggestions for considering dimming of road lighting based on recent developments in science and technology are provided. The three recommended approaches, static road lighting, semi-dynamic lighting levels, and dynamic lighting levels, could save energy without compromising traffic safety.
\end{abstract}

KEYWORDS: road lighting, car headlights, dimming, night visibility, energy saving

\section{Introduction}

Traffic collisions are a leading cause of death worldwide, accounting for 1.4 million fatalities in $2016^{1)}$. The literature on traffic collisions has highlighted contributing factors such as low visibility ${ }^{2-4)}$ alcohol or drugs ${ }^{5,6)}$, distraction $^{7,8)}$ and fatigue ${ }^{9,10)}$. Evidence suggests that the number of collisions is higher during darkness than daylight. Road lighting can play a role in counteracting low night-time visibility ${ }^{2-4)}$. A summary of studies of night-time collision reductions associated with lighting converged on an average $30 \%$ nighttime crash reduction in the presence of road lighting ${ }^{2}$, although when controlling for confounding factors, the night-time reduction associated with road lighting may be closer to $10-15 \%{ }^{12-14}$. Despite the safety impacts, the energy cost for road lighting is an issue that requires attention ${ }^{15,16)}$. Road lighting globally consumes $218 \mathrm{TWh}$ of electricity annually, amounting to about $8 \%$ of lighting consumption $^{16)}$. Therefore, energy-saving is a critical driving force in the development of lighting solutions.

Intelligent road lighting technologies have made energy and cost savings more readily possible. The Commission Internationale de 'I'Eclairage, CIE, provides design guidance for national and regional recommendations worldwide to meet traffic and pedestrian flow needs.
Intelligent road lighting based on CIE adapts to the changes at different time intervals. Step-wise dimming is one intelligent road lighting practice using different control parameters including time-schedule-based stepdimming, and traffic volume- and weather-based stepdimming. Time-schedule-based step-dimming controls light output at specific times. Such step-dimming is simple and reduces the light level based on time intervals, enabling energy savings when road usage is low. However, this dimming strategy does not adapt to the real-time needs of traffic ${ }^{17}$. Traffic volume and weatherbased step-dimming strive to adjust light output to varying weather and traffic conditions. When snow covers the road, or when traffic is low, the illumination level can be reduced ${ }^{18)}$. These practices are based on the reduced need for light on snow-covered roads; thus, the illumination could be reduced ${ }^{14,}{ }^{19}$. In addition, by detecting an increase in traffic, the road lighting could increase ${ }^{18)}$. However, in heavy traffic, drivers are unlikely to be concerned with detecting targets at a distance but rather with the vehicle immediately ahead ${ }^{15}$.

Although step-dimming conserves energy, even more energy could be saved in the presence of car traffic. Aside from illumination by road lighting, vehicles have headlights. Car headlights ideally provide sufficient

\footnotetext{
${ }^{\dagger}$ Corresponding Author: Sanaz Bozorg sanaz.bozorg@cambridgeshire.gov.uk
} 
lighting far enough ahead in the field of view for a driver to see a hazard while minimising light facing oncoming traffic ${ }^{20-22)}$. Consequently, the combination of the illumination from car headlights and, when present, road lighting influences drivers' visual performance. The combined effects of road lighting and car headlights have been studied broadly and indicate that their effects are not always complementary ${ }^{15,}$ 19, 22-28). While road lighting illuminates the road surface (horizontally), car headlights illuminate vertical objects on the road, and the combined effect of road lighting and car headlights may reduce the contrast of objects on the road. For instance, Bacelar ${ }^{24)}$ studied the combined effect of headlights and road lighting at different distances $(40$ or $90 \mathrm{~m})$ from the headlights along the road. The cumulative effects of headlights and road lighting were not complementary, and each separately could result in better visibility than when used together. Bacelar noted that the distance to the target was a key contributing factor in the contrast between the target and the road surface. For instance, low-beam headlights did not contribute to the detection of targets when the distance exceeded $90 \mathrm{~m}$ from the target. However, high-beam headlights contributed to target detection at these larger distances. This is important because drivers often do not use their high beam headlights ${ }^{29,30}$. Similarly, Ekrias et al. $^{31)}$ found that the joint use of car headlights and road lighting did not improve the luminance contrast of the targets on the road. The impacts were dependent on the type of headlights, the reflection and position of the target, the car's position, and the road lights. Due to high costs and the noncomplementary effect of road lighting and car headlights, most motorways in the U.S. are not illuminated, and some government agencies have considered turning off road lighting ${ }^{22}$.

As previously noted, however, road lighting has been generally found to have a positive effect on traffic safety (e.g. $\left.{ }^{2}\right)$. There are several other reasons that unlit roads might be less safe for traffic. First, road lighting can compensate for the limited effectiveness of headlights distribution (beam distance and shape), especially for detecting targets at far distances ${ }^{32}$. Second, road lighting mitigates the relative impact of additional scattered light in the eyes coming from oncoming cars (glare from oncoming traffic) ${ }^{24)}$. Consequently, intelligent road lighting practices should be based on different traffic demands in order to ensure traffic safety while saving energy.

This review seeks to briefly compare CIE road lighting guidelines with current knowledge of motorway lighting. Subsequently, new considerations for intelligent road lighting into guidelines are described.

\section{Background}

Before understanding how intelligent road lighting can save energy, it is necessary to consider visual performance and visual comfort, which can directly affect traffic safety ${ }^{33)}$.

\subsection{Visual performance and visual comfort}

Visual comfort and performance are important aspects of night-time driving safety. Visual comfort is a subjective aspect of road-lighting quality and contributes to drivers' alertness. For instance, driver fatigue will increase in a low degree of visual comfort, and consequently, visual performance and alertness could decrease $^{33)}$. Light level, uniformity, and glare related to road lighting all affect visual comfort, which in turn could affect visual performance ${ }^{33)}$. Several factors affect visual performance and visual comfort for motorised traffic $^{15,19,22-28)}$; Figure 1 lists some of the main ones.

A brief overview of previous research on each factor is important before suggesting and employing any intelligent practices.

\subsubsection{Artifical lighting \\ 2.1.1.1 Car headlights}

Car headlights are by far the primary source of illumination for drivers. The effectiveness of headlights is limited by their distribution (beam distance and shape) and the car's speed ${ }^{32}$. The distribution is represented in terms of luminous intensity and illuminance pattern.

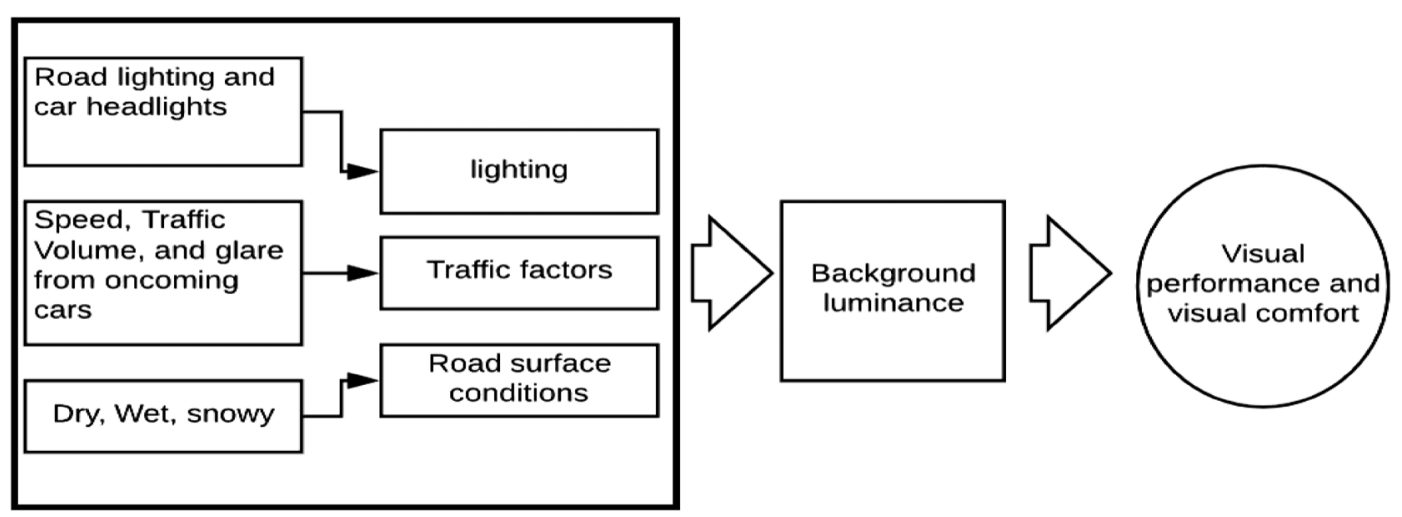

Figure 1 Factors influencing visual performance and visual comfort. 
Low- and high-beam headlights are the two distributions required by law. Although multiple headlight design characteristics affect light distribution (i.e. lamp construction), the required photometric properties of headlights are given as luminous intensity minima and maxima for specific directions relative to the beam $\operatorname{axis}^{15)}$.

Two concepts, headlight distribution and speed, are central to the concept of over-driving headlights and the assured clear distance ahead (ACDA) rule. Overdriving headlights refers to not being able to stop in time to respond to a hazard illuminated by headlights because of excessive speed, and the ACDA rule requires drivers to maintain their speed low enough to enable the driver to stop within the range of vision and therefore, to avoid traffic collisions with any obstacles that might appear in the car's path ${ }^{32}$.

One criterion to examine the effectiveness of car headlights in relation to speed is detection distances under different speeds. Previous studies have reported that typical low beam headlights provide enough visibility to respond to hazards while driving at speeds only up to $50 \mathrm{~km} / \mathrm{h}$ under optimum conditions without oncoming glare ${ }^{20,27,34)}$. Perel et al. ${ }^{20)}$ examined U.S. and European headlamps in a detection distance study. With U.S. low beams, mean visibility distances to pedestrian targets ranged from about 30 to $120 \mathrm{~m}$. In the presence of opposing traffic detection distances were only about 25 to $80 \mathrm{~m}$. Comparisons between detection distances and stopping distances suggested that the maximum safe speed when using low beams was between 20 and $55 \mathrm{mph}(32-88 \mathrm{~km} / \mathrm{h})$ under normal conditions, without glare from an oncoming car. The differences in the speed range could be explained by different study designs, such as the difference in targets, tests, alert/unalert subjects, etc ${ }^{20}$. The bottom range of the detection distance by Perel et al. ${ }^{20)}$ suggests that the safe speed for driving with low beam headlights was $48 \mathrm{~km} / \mathrm{h}(30 \mathrm{mph})^{15)}$.

\subsubsection{Road lighting}

Road lighting is considered as a secondary type of artificial lighting on the road, which could be useful in the detection of targets that are far from car headlight illumination, especially on roads with high-speed limits. Several studies have indicated that road traffic collision risk is lower on lit roads than unlit ones, ${ }^{33}$. It is now well-established that road lighting reduced night-time collisions for all road types by on average $30 \%{ }^{2}$. However, this value may be larger than lighting actually provides because many of the studies reviewed by the CIE did not control for many safety-related factors in addition to lighting. Lighting for motorised traffic in CIE recommendations is based on five criteria: average light level $\left(\mathrm{L}_{\text {ave }}\right)$, uniformity $\left(\mathrm{U}_{0}\right.$ and $\left.\mathrm{U}_{1}\right)$, glare restriction (TI), and surround ratio (SR). The light level is the average luminance of the road surface between 60 and $160 \mathrm{~m}$ in front of the driver. Uniformity refers to the ratio of the minimum to the average road-surface luminance $\left(\mathrm{L}_{\text {min }} / \mathrm{L}_{\text {ave }}\right)$. The surround ratio (SR) attempts to ensure that the cut-off of the light at the kerbside is not too sharp. The amount of glare produced by road lighting is also defined for each road lighting class. Higher values of TI correspond to greater disability glare. The formula for calculating TI is: $\mathrm{TI}=65 \mathrm{~L}_{\mathrm{v}} /\left(\mathrm{L}_{\mathrm{ad}}\right)^{0.8}$, where $\mathrm{L}_{\mathrm{v}}$ is veiling luminance and $\mathrm{L}_{\mathrm{ad}}$ is adaptation luminance.

\subsubsection{The combined effect of road lighting and car headlights}

Car headlights and road lighting have been developed separately. Together, however, they form three zones of visibility ${ }^{15}$. In the near zone, visibility is dominated by headlights, while in the intermediate zone car headlights and road lighting have a combined effect. In the far zone road lighting alone contributes to visibility. There are conflicting effects between car headlights and road lighting in the intermediate $z o n e^{22,} 23,25-27$. To avoid these conflicting effects, several researchers focused on the visibility performance of drivers considering both technologies. To eliminate this conflicting effect, some studies suggest reducing the effect of car headlights (e.g., city beam) $\left.{ }^{23}, 35,36\right)$ and others suggest to alter the road lighting ${ }^{37}$.

For example, Akashi et al. ${ }^{23)}$ measured detection distances in their study under three road lighting levels (2-20lux), three headlight levels $(100 \%, 30 \%, 10 \%)$, and five target positions (eccentricity, $-15^{\circ},-5^{\circ}, 0^{\circ}, 5^{\circ}$, and $15^{\circ}$ ). All main effects and interactions were statistically significant. Figure 2 illustrates the eccentricty relative to the line of vision. The main results of their study suggest that recognition distance increased as road lighting increased. The effect of road lighting on recognition distance became smaller as the target eccentricity angle increased $\left(15^{\circ}\right.$ to the right). Finally, at lower eccentricities ( \pm 5 degrees and below) the effect of headlights intensity on recognition distance was smaller than that of road lighting illuminance. Their recommended city beam would have a wider luminous intensity distribution than the normal distribution to make peripheral targets visible.

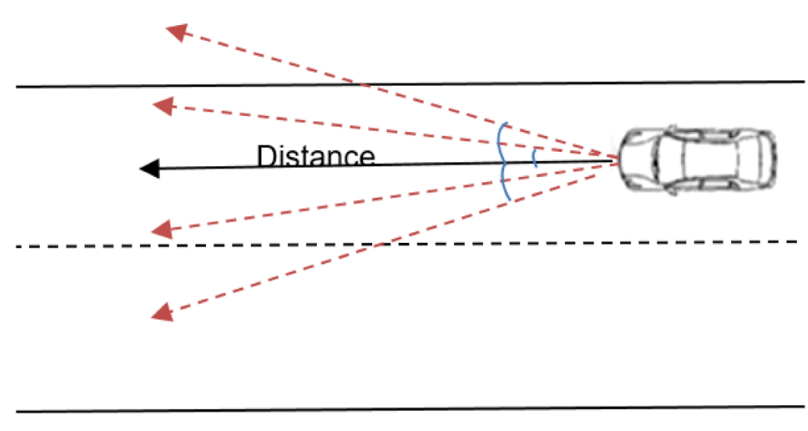

Figure 2 Eccentricity in relation to driver's line of sight. 
Similar conclusions were found in the study by Ekrias et al. ${ }^{31}$, which indicated that when both road lighting and car headlights were on, the luminance contrast was lower compared to when only road lighting was on. In addition, low-beam headlights had little effect on target contrast when the distance between the target and the car was more than $80 \mathrm{~m}$. At shorter distances, the effect of car headlights was larger. They suggested using parking lights instead of low-beam headlights when road lighting is present. They argued that reducing the effect of car headlights made the visibility of other cars and surroundings completely dependent on road lighting ${ }^{31}$.

As drivers can always rely on their headlights, the vast majority of studies support altering road lighting level to both remove noncomplementary effects of car headlights and road lighting and save energy ${ }^{22,38,39}$. For instance, Oya et al. $^{38)}$ compared visibility under road lighting and under a combination of car headlights and road lighting. Their results indicated that with only road lighting, objects were mainly seen in silhouette vision. Under a combination of car headlights and road lighting, they could be seen in silhouette vision or reversed silhouette vision (Figure 3 illustrates silhouette and reverse silhouette vision). They tried to increase silhouette vision by turning the optical axes of luminaires toward drivers to improve the road surface luminance and obstacle visibility. Visibility Level values under their improved system were greater than under the previous system at many points, but there were several problems. First, the new system provided an asymmetric light distribution due to turning the optical axes toward the drivers; thus the spacing between luminaires should be examined before making any decisions on using this system. Also, in the case of two-way traffic, if luminaires are arranged on one side only, there is no effect on the lanes of the other side of the road. If luminaires are arranged on both sides, it is necessary to examine the light distribution and spacing of luminaires in order to eliminate the influence on the lanes of the other side ${ }^{38)}$.

A study by Bullough and $\mathrm{Rea}^{22)}$ also illustrates the non-complementary effect of road lighting and car headlights by comparing visibility in different scenarios. They used different headlights (halogen low-beam, HID low-beam, and halogen high-beam), road lighting conditions (no lighting, a single road luminaire with average horizontal illuminance of $15 \mathrm{~lx}$, and continuous road lighting with average horizontal illuminance of $15 \mathrm{~lx}$ in the conflict area of the intersection and $91 \mathrm{x}$ on the surface of the major road), and ambient illuminances $(20,2,0.2$ and $0.021 \mathrm{x})$. At $20 \mathrm{~m}$ from the car, the highest vertical illuminance on targets was provided by low beam HID headlights, followed by high beam halogen headlights and lastly by low beam halogen headlights. At $40 \mathrm{~m}$ from the car, the highest vertical illuminance on targets was provided by the high beam halogen headlights, then by low beam HID, and low beam halogen headlights, respectively. In addition to the vertical illuminance by headlights, Bullough and $\mathrm{Rea}^{22)}$ used the relative visual performance (RVP) model ${ }^{40,41)}$ to study visibility for different scenarios. With no road lighting, the low beam HID headlamp resulted in the best visual performance with little difference between the halogen low beam and the high beam headlamp beam patterns. This is due to the broader HID beam pattern relative to halogen headlamps as well as having higher vertical illuminances than the other options. With a single road luminaire, the differences among the headlights beam patterns were reduced greatly, although there was still a small advantage of the HID headlamp beam pattern. With continuous road lighting, the differences among the headlamp beam patterns were negligible. Under the highest ambient illuminances (2 or 20lx) and independent of the car headlighting beam pattern, visual performance was high, with RVP values of about 0.9

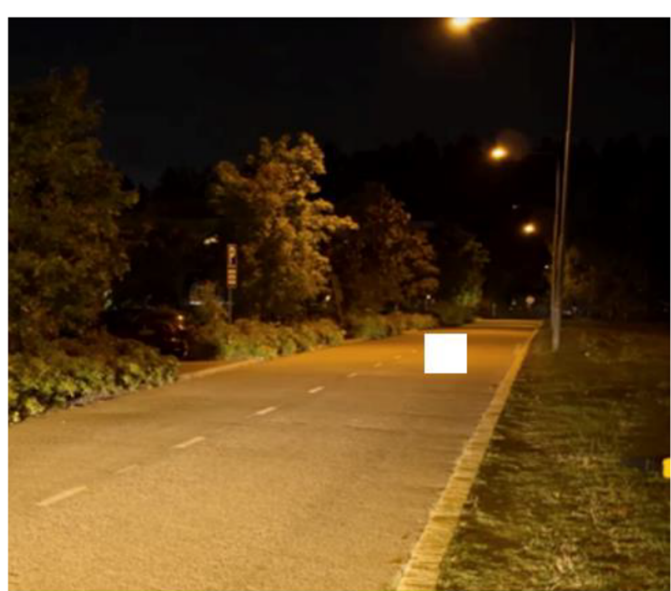

a)

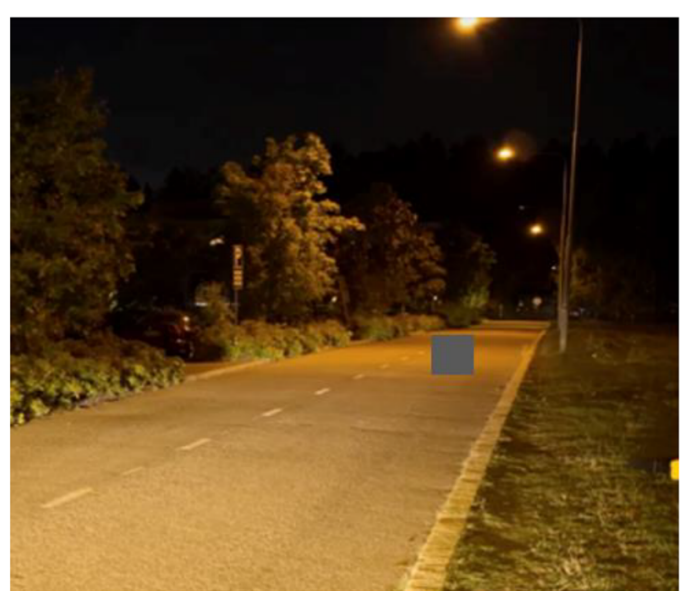

b)

Figure 3 a) reversed silhouette vision (object lighter than the background), b) silhouette vision (object darker than the background). 
or higher. For targets located $40 \mathrm{~m}$ ahead and no road lighting, the highest RVP was provided by high beam halogen, then by low beam HID, and low beam halogen headlights, respectively. Adding a single road luminaire or continuous road lighting, the visual performance of targets located at $40 \mathrm{~m}$ was still high, independent of the effect of road lighting ${ }^{22}$.

In addition, Bozorg et al. ${ }^{39)}$ assessed the visual performance of drivers in recognising small targets located in different positions between two poles under different reduced lighting conditions in a stationary car with low beam headlights. The results indicated a non-complementary effect of road lighting and headlights; they also found that visibility performance was not a monotonic function of light level. The best condition for the visibility of targets was the lowest studied lighting level [49\% (3557 lm per luminaire) of the full road lighting output], the second-best road lighting condition was full (100\%) road lighting $(7552 \mathrm{~lm})$, and the worst was $71 \%(5179 \mathrm{~lm})$.

Bacelar $^{24)}$ found that with only headlights, visibility performance of drivers' was constant at constant distances from the car. Visibility performance with different headlights (low beam versus high beam) was different depending on the distance of target with headlights, the lower the distance the better the visibility. This is due to the various illuminance on the target and target angular size at different distances. With only road lighting, visibility performance was different at different locations due to the light distribution. Finally, he noted that using road lighting and low-beam car headlights separately results in better visibility than when they were used together.

Although differences of opinion exist, there appears to be some agreement on the non-complementary effect of road lighting and car headlights in the intermediate zone. Research has conclusively been shown that 1) the effect of car headlights is limited to its distribution and speed, 2) the combined effect of car headlights and road lighting is not complemenrty in the intermediate zone, and 3) the effect of road lighting is distinct in the far zone. Consequently, the evidence from the previous studies consistently emphasises the importance of considering the combined effect of road lighting and car headlights in the design of intelligent road lighting. Drivers' ability to detect approaching hazards in the dark is not only based on the combined effect of road lighting and car headlights but also on other factors. Therefore, it is important to assess other factors that might have an impact on detecting a hazard on the road.

\subsubsection{Traffic factors}

Traffic volume, speed, and the effect of glare from oncoming cars are some main factors that affect visibility performance of drivers (Figure 1).

\subsubsection{Traffic volume}

As was mentioned in the previous section, headlight illuminance is enough for nighttime driving under many conditions, and it is only beyond the range of low beam headlights that the role of road lighting is significant. As a result, it can also be expected that in high traffic volume when cars are following each other with low speed and the distance between them is small, there is not much light required from road lighting. It can be expected that in very dense traffic, road lighting might have little contribution to visual performance because car headlights dominate what needs to be seen, while in medium or low traffic, the effect of road lighting may only be significant beyond the range of low-beam headlights ${ }^{15)}$. The effect of lighting levels on different roadway types was analysed using the relationship between horizontal illuminance and weighted night-to-day crash rate ratio by roadway functional class ${ }^{42}$. The result suggested minimum horizontal limits for urban interstate, urban principal arterial, other principal arterial and minor arterial to be 5, 7.5, 13, and 16 lux, respectively. Beyond these minima, an increase in illuminance did not have an effect on the overall traffic safety. Gibbons et al. $^{42)}$ explained the difference in lighting level requirements by traffic volume and potential conflict with other cars and driveways. For instance, minor arterials with lighting are safer (i.e., they experience fewer collisions) during nighttime than during daytime due to lower traffic volumes and fewer conflicts with other cars at nighttime. Overall their observation supports the use of lower lighting levels in low traffic densities without compromising traffic safety.

\subsubsection{Speed}

As stated, a safe speed for driving with only car headlights is $48 \mathrm{~km} / \mathrm{h}(30 \mathrm{mph})^{15,20)}$. Above this speed, nighttime drivers might be violating the ACDA rule, meaning that the car cannot stop inside the illuminated area ahead. Consequently, road lighting is necessary for visibility along high-speed roads.

\subsubsection{Effect of glare from oncoming cars}

When driving at night, glare from oncoming cars is unavoidable. Such effects adversely affect visual performance of drivers ${ }^{43,44)}$. Important characteristics of headlights related to discomfort and disability glare while driving at night, [i.e., intensity, spectrum, size and temporal properties (frequency, duration) of headlights] were comprehensively investigated by Bullough et al. ${ }^{45)}$. Bacelar ${ }^{24)}$ studied the amount of disability glare from an oncoming car by placing a luminance meter on two directions directions: 1) parallel to the axis of the car (resembling a driver looking straight forward), and 2) toward the left optic of the opposing car. The measurement car had low-beam headlights, road lights were either switched on or off, and the car producing glare was at different distances from the measurement car. 
The results indicate that when the luminance meter was aimed straight ahead, the maximum contribution of the car headlights was between $0.1-0.25 \mathrm{~cd} / \mathrm{m}^{2}$ depending on the distance from the headlights with the maximum effect at a distance of $30 \mathrm{~m}$. The effect was almost ten times higher when the luminance meter was in the direction of opposing headlights. Bacelar ${ }^{24)}$ also studied the VL of a flat target $(20 \mathrm{~cm} \times 20 \mathrm{~cm}$ targets with a reflectance of $20 \%$ ), with and without road lighting when influencing with one or three opposing cars. On a lit road when the driver's eyes were directed to the single opposing car headlights, visibility was reduced by at least $30 \%$ and up to $50 \%$ when affected by three oncoming cars. When the driver's eye was looking forward, the VL reduction was between $15-20 \%$ in the case of one car or three cars respectively. VL in the presence of glare from an oncoming car was more affected along an unlit road than along a lit road. When there was no road lighting and the driver looked straight ahead, VL was reduced by $40-50 \%$. In the presence of glare from an oncoming car, drivers' visual performance was more affected on unlit roads than on lit roads. Lighting improved the visual adaptation of the driver. To sum up, disability glare from oncoming traffic can adversely affect visibility comfort and performance, and road lighting reduces the effect of disability glare from oncoming cars. However, Bacelar did not consider the effect of different road lighting levels in his study. Bozorg et $\mathrm{al}^{27,41)}$, experimented the effect of different road lighting levels $(3557,5179$ and $7252 \mathrm{~lm})$ on driver's visibility performance who affected by glare from an oncoming car. Their detection distance study indicated that an average illumination of 4.28lux from road lighting provided detection distances comparable to those provided by full road lighting (average illumination of 8.3lux) when driving at $30 \mathrm{~km} / \mathrm{h}^{27)}$. They found similar results on their stationary car study ${ }^{41)}$, no statistically significant effect among studied road lighting levels on visibility was found, however, full road lighting provided on average better visibility.

\subsubsection{Road surface conditions}

Another important parameter altering the luminance of the road surface, thus affecting visual performance, is the presence of different weather conditions. For instance, Ekrias et al. ${ }^{19)}$ found that the luminance level of a snowy road was multiple times higher than that under dry conditions. Even when there was little or no snow on the road itself, luminance levels were still $50 \%$ higher compared with dry conditions. Also, Wanvik ${ }^{4)}$ found that the luminance level of a snow-covered road surface was increased by a factor of 4 or 5 compared with a dry road.

Ekrias et al. ${ }^{19)}$ monitored luminance levels of different road surface conditions (dry, wet, and snowy). The luminance level of a snowy road was many times higher than under dry road conditions. Luminance levels were $50 \%$ higher than under dry condition even when the road was only lightly covered by snow or had been cleared. Also, the average luminance level was higher in the wet road surface than in dry conditions. However, wet road surface had a specular reflection, which leads to the lower uniformity than in dry conditions. Low uniformity could cause discomfort for drivers. The authors suggested that real-time measurements of luminance can be used in intelligent road lighting practices. However, the emphasised the importance of the luminance meter location and the measurement area. They noted that the meter should be located close to the drivers' position and measure the road surface between one luminaire spacing, and in the transverse direction, the area should be defined by borders of a carriageway.

A very recent study by Bozorg et al. ${ }^{28)}$ examined the visibility level of two objects $(20 \times 20 \mathrm{~cm}$ targets with a reflectance of $50 \%$ and a pedestrian with the reflectance of 3.3\%) under varying road surface conditions (dry, wet and snowy), road lighting levels $(0.75,0.53,0.38,0.19$, $0 \mathrm{~cd} / \mathrm{m}^{2}$ ). The distance between the objects and the car headlights was constant. Thus, the car and the objects were moved after each measurement to maintain a constant distance of $80 \mathrm{~m}$ between the objects and car headlights. The objects were in two different longitudinal locations: the standard target was always placed in the middle of the lane (central axis), and the pedestrian was on right axis, near the carriageway. Their results indicated that the average luminance level of the wet road surface is 2.5 times higher than in dry conditions, but it has non-uniform specular reflections. In addition, the average luminance level of the snowy road surface was 3 times higher than dry or normal conditions. They concluded that VL was not a monotonic function of road lighting. In the case of the standard target, over all surface conditions, the unlit road had the best VL. The second best was road lighting with $\mathrm{L}_{\text {ave }}=0.19 \mathrm{~cd} / \mathrm{m}^{2}$. In the case of the pedestrian, the same pattern could be seen in dry conditions. In wet and snowy conditions, $\mathrm{L}_{\mathrm{ave}}=0.75 \mathrm{~cd} / \mathrm{m}^{2}$ provided the best visibility. For other lighting levels visibility reduced in the order $\mathrm{L}_{\text {ave }}=0.53,0$, 0.19 and $0.38 \mathrm{~cd} / \mathrm{m}^{2}$ and $\mathrm{L}_{\text {ave }}=0.38,0.53,0.19$ and $0 \mathrm{~cd} / \mathrm{m}^{2}$ respectively for the wet and snowy road surface.

A conclusion can be derived from these studies that the demand of road lighting level differs in different circumstances. Therefore, road lighting should not be considered as a digital variable (on/off) and should address different conditions.

\subsection{Traffic safety}

In order to understand the relationship between different lighting levels and traffic collisions, Gibbons et al. $^{42)}$ used five criteria: 1) horizontal illuminance, 2) 
vertical illuminance, 3 ) vertical-to-horizontal illuminance ratio (effect of glare), 4) lighting uniformity measure which was the difference in local maximum and local minimum lighting levels caused by the location of a lighting pole or by other factors; it is important to note that car headlights were considered in this measurement, and 5) luminance. They reported that current road lighting practices result in over-lighting and higher road lighting is not associated with safer roads. They suggested the following values for the above-mentioned criteria: 1) a minimum average horizontal illuminance of 5lux, 2) a minimum average vertical illuminance of 3 lux, 3) a vertical-to-horizontal ratio of $0.6,4$ ) a minimum uniformity of 0.3 , and 5) they could not find any significant trend in the relationship between luminance and night-day-crash-rate-ratio. However, they noticed that an increase in the luminance may increase the crashrate ratio. Finally they concluded that night-day-crash rate- ratio is significantly smaller in the luminance level of $0.15 \mathrm{~cd} / \mathrm{m}^{2}$ than other luminance levels, considering the effect of car headlights.

In addition, Monsere et al. ${ }^{46)}$ investigated the relationship between a $10 \%$ reduction in the power of road lighting consumption and traffic collisions in three settings. Their results indicated that where the lighting was reduced from full ${ }^{* 1}$ to partial lighting*2 design at intersections, night-time collisions increased by less than $4 \%$. Where the lighting was reduced from a partialplus design to a partial design at intersections, collisions decreased by $35 \%$. Finally, where mainline lighting was reduced or removed at highways sections, collisions increased by nearly $30 \%$, and fatal and injury collisions increased by nearly $40 \%$. However, Monsere et al. do not suggest that reducing roadway lighting leads to a definitive safety benefit. Gibbons et al. ${ }^{45)}$ argued that the results provided by Monsere et al. ${ }^{46)}$ are not robust because the sample size was small and the roadways where the lighting was reduced were selected based on their history of safety, which might affect the results.

Although this study does not focus on the effect of illumination on traffic safety, no evidence could be found that different illumination could affect crime and contribute to the feeling of security ${ }^{47-49}$. Steinbach and others ${ }^{47}$ focused on the effect of different road lighting practices on traffic safety and crime prevention. They did not find any evidence for an association between the aggregate count of crime and switch off or part-night lighting. There was weak evidence for a reduction in the ag-

\footnotetext{
${ }^{* 1}$ Full lighting describes interchange lighting where all critical points such as gore areas, terminal on surface streets, merge points, curbs, piers, and abutments are lit as well as points in between.

*2Partial plus is design that has more lighting than Partial lighting design but less than full lighting.
}

gregate amount of crime with dimming and white light. They suggested that local authorities can safely reduce road lighting levels to save both costs and energy without negatively impacting road traffic collisions and crime.

Consequently, the combined effect of road lighting and car headlights, the speed of the car, traffic volume, absence/presence of glare from oncoming traffic, and luminance of road surface during different weather conditions should be considered in designing intelligent road lighting.

\subsection{Description of current dimming guidelines}

As CIE provides the primary basis for other national and regional recommendations, this study focused on CIE recommendations to gain a detailed understanding of road lighting guidelines and current knowledge about motorised traffic. Therefore, the outcome of this study could be adopted to other recommendations. According to CIE there are four different lighting classes: formotorised traffic, for traffic conflict areas, and for pedestrians and low-speed traffic. This article focuses on the lighting for motorised traffic (M lighting class) ${ }^{50)}$. Several weighting values for different parameters have to be selected and added to find the sum of the weighting values $\left(\mathrm{V}_{\mathrm{W}}\right)$. Table 1 indicates the selection param-

Table 1 Selection parameters for motorised traffic ${ }^{50)}$.

\begin{tabular}{|c|c|c|}
\hline Parameters & Options & $\begin{array}{l}\text { Weighting } \\
\text { values }\end{array}$ \\
\hline \multirow{3}{*}{ Speed limit } & Very high & 1 \\
\hline & High & 0.5 \\
\hline & Moderate & 0 \\
\hline \multirow{5}{*}{ Traffic volume } & Very high & 1 \\
\hline & High & 0.5 \\
\hline & Moderate & 0 \\
\hline & Low & -0.5 \\
\hline & Very low & -1 \\
\hline \multirow{3}{*}{ Traffic composition } & $\begin{array}{l}\text { Mixed with high percentage } \\
\text { of non-motorised traffic }\end{array}$ & 2 \\
\hline & Mixed traffic & 1 \\
\hline & Only motorised & 0 \\
\hline \multirow{2}{*}{$\begin{array}{l}\text { Separation of } \\
\text { carriageway }\end{array}$} & No & 1 \\
\hline & Yes & 0 \\
\hline \multirow{2}{*}{ Intersection density } & High & 1 \\
\hline & Moderate & 0 \\
\hline \multirow{2}{*}{ Parked vehicles } & Present & 0.5 \\
\hline & Not present & 0 \\
\hline \multirow{3}{*}{ Ambient luminance } & High & 1 \\
\hline & Moderate & 0 \\
\hline & Low & -1 \\
\hline \multirow{3}{*}{$\begin{array}{l}\text { Visual guidance } \\
\quad \text { (traffic control) }\end{array}$} & Poor (difficult) & 0.5 \\
\hline & Moderate (normal) & 0 \\
\hline & $\begin{array}{l}\text { Sum of Weighting values } \\
M=6-V_{w} \text { Class }\end{array}$ & \\
\hline
\end{tabular}


Table 2 Recommended luminance values by CIE recommendations ${ }^{5}$.

\begin{tabular}{|c|c|c|c|c|c|c|}
\hline \multirow{2}{*}{$\begin{array}{l}\text { Lighting } \\
\text { class }\end{array}$} & \multicolumn{2}{|c|}{ Dry } & \multicolumn{2}{|c|}{ Wet } & \multirow{2}{*}{$\begin{array}{l}\text { TI } \\
(\%)\end{array}$} & \multirow[b]{2}{*}{ SR } \\
\hline & $\begin{array}{c}\mathrm{L}_{\text {ave }} \\
\left(\mathrm{cd} / \mathrm{m}^{2}\right)\end{array}$ & U0 & Ul & U0 & & \\
\hline M1 & 2.0 & 0.40 & 0.70 & 0.15 & 10 & 0.5 \\
\hline M2 & 1.5 & 0.40 & 0.70 & 0.15 & 10 & 0.5 \\
\hline M3 & 1.0 & 0.40 & 0.60 & 0.15 & 10 & 0.5 \\
\hline M4 & 0.75 & 0.40 & 0.60 & 0.15 & 15 & 0.5 \\
\hline M5 & 0.50 & 0.35 & 0.40 & 0.15 & 15 & 0.5 \\
\hline M6 & 0.30 & 0.35 & 0.40 & 0.15 & 20 & 0.5 \\
\hline
\end{tabular}

eters and weighing values $\left(\mathrm{V}_{\mathrm{w}}\right)$.

The number of the lighting class $\mathrm{M}$ is then calculated. The results will yield class numbers between M1-M6 as shown in Table 2.

The demand for light intensity differs for various seasons, traffic volume and ambient brightness. Therefore, in addition to the static road lighting class, CIE defines adaptive road lighting in which the lighting is dimmed based on changes in traffic volume and weather conditions at four-time intervals $\left(\Delta t_{1}, \Delta t_{2}, \Delta t_{3}\right.$, and $\left.\Delta t_{4}\right)$. From switch-on time until the end of rush hour $\left(\Delta t_{1}\right)$, from end of the evening rush hour until midnight $\left(\Delta t_{2}\right)$, from midnight until the beginning of morning rush hour $\left(\Delta t_{3}\right)$, and from the beginning of morning rush hour until switch off time $\left(\Delta t_{4}\right)^{50)}$. Therefore, during $\Delta t_{2}$ and $\Delta t_{3}$ when traffic volume is lower than rush hour, road lighting can be reduced, or when the road is snow-covered, the luminance level would tend to be higher than normal, providing an opportunity to reduce road lighting.

Several intelligent road lighting systems across Europe have been installed through the intelligent road and street lighting project known as E-Street ${ }^{51,52)}$. Overall, 20,000 intelligent road lights (adaptive luminaires) were installed throughout Europe in 2006-2008 in which an annual saving potential of $38 \mathrm{TWh}$ electricity was estimated by retrofitting old installations with intelligent road lighting. This represents approximately $64 \%$ of the annual energy consumption of road lighting. The reason for the large-scale pilot of intelligent road lighting was based on the understanding that the demand for lighting is reduced when there is little traffic on the road. However, there is still the potential to use different road light levels.

\section{The need for reconsideration of CIE guidelines}

Eight factors affecting the selection of road lighting level include: speed limit, traffic volume, traffic composition, separation of the carriageways, intersection density, parked vehicles, ambient luminance, and visual guidance. Intelligent road lighting by CIE uses the same selection parameters as static road lighting classes; it only compares traffic volume and weather
Table 3 Recommended luminance values by CIE recommendations, the arrows coded as a recommended increase $\nearrow$.

\begin{tabular}{lcc}
\hline \multicolumn{1}{c}{ Parameters } & Changes & Lighting level \\
\hline Ambient luminance & $\nearrow$ & $\nearrow$ \\
Speed limit & $\nearrow$ & $\nearrow$ \\
Traffic volume & $\nearrow$ & $\nearrow$ \\
\hline
\end{tabular}

Note: An upward-pointing arrow represents an increase, and a downward pointing arrow represents a decrease.

conditions during different time spans which could lead to different lighting class during the night ${ }^{50}$.

Despite the widespread use of CIE guidelines, there are several concerns associated with it that need to be considered. To limit the scope of this article, traffic composition, intersection density, parked vehicles, visual guidance and separation of the carriageway are not discussed here and might need to be studied further. Therefore, a careful analysis of a) ambient luminance, b) speed limit, and c) traffic volume is provided in this section. Table 3 summarises the influence of changes in these factors on lighting level based on CIE recommendation ${ }^{50)}$.

To elaborate on Table 3 (which is based on Table 1), CIE recommended that, higher ambient luminance, traffic volume, and speed limits correspond to the higher lighting level.

This review is originated from Bozorg's ${ }^{53)}$ doctoral dissertation, where the author's scope was investigating driver visual performance on different scenarios to find out possibilities to alter road lighting. In continuity with the thesis, this review has set out to suggest on intelligent road lighting practices to adjust road lighting level based on demand. Therefore, a more detailed literature review could be found on her doctoral dissertation.

\section{Discussion}

Road lighting for motorised traffic should correspond to the variable needs of traffic throughout the night. Current knowledge provides some insights into reconsideration of CIE recommendations for both static and intelligent road lighting systems to reduce energy and cost consumption without adversely affecting traffic safety. Figure 4 summarises the parameters that can change throughout the night and can influence the required lighting level for motorised traffic:

- Road surface conditions,

- The combined effect of road lighting and car headlights,

- Glare from oncoming traffic,

- Traffic volume, and

- Speed

Intelligent road lighting practices should involve the active integration of the above-mentioned parameters. This review describes the three parameters in the CIE 


\section{- Combined effect of road lighting and car headlights}

涫

?

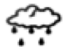

- Ambient light

- Weather conditions

- Speed

- Traffic volume

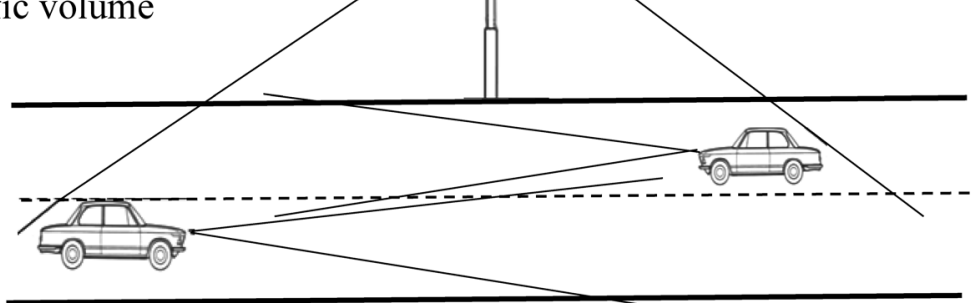

Figure 4 Parameters that change throughout the night that influence lighting level.

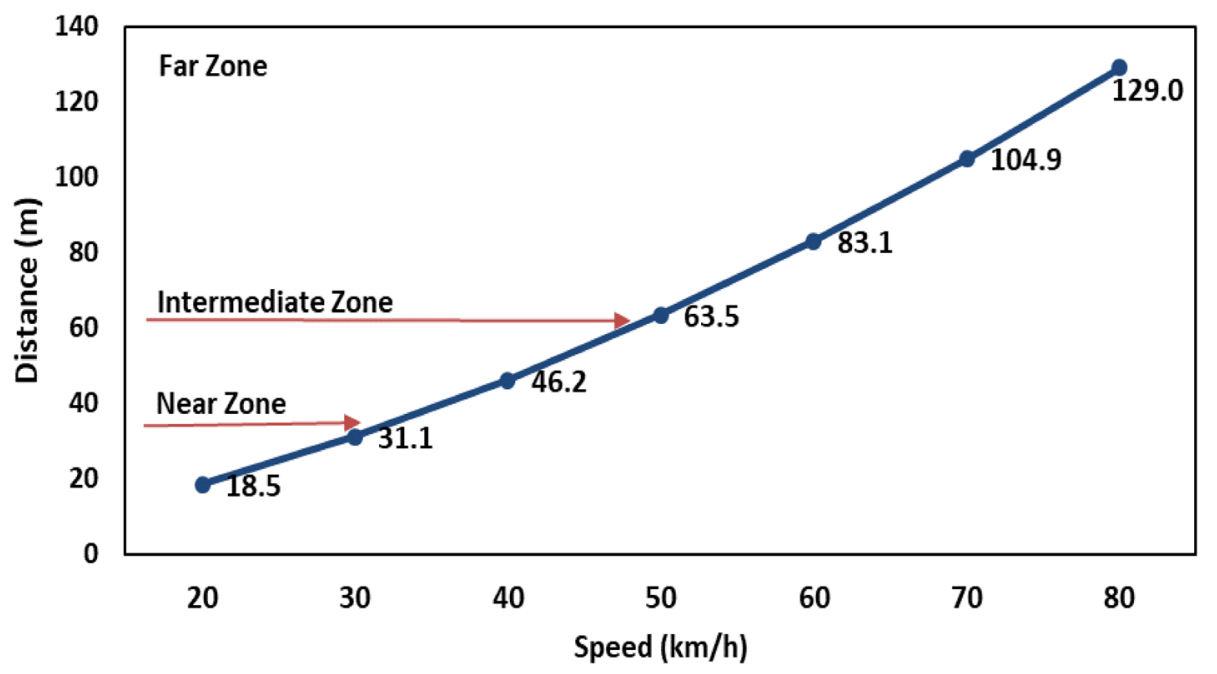

Figure 5 Stopping distances for a range of design speeds (based on Table 3-I of AASHTO's Policy on Geometric Design of Highways and Streets; 2001, p. 112), plus zones of visibility ${ }^{56)}$.

lighting recommendations that can be altered throughout the night and can be used in order to alter road lighting level: ambient luminance, speed limit, and traffic volume.

The first argument is that when there is no traffic there is no need for full road lighting. Therefore, it is possible to reduce energy cost by dimming road lighting to the possible dimmed level or even off during the time there is no traffic. In preference of traffic, however, car headlights also provide some illumination. As discussed the combined effect of car headlights and road lighting are not always complementary.

Numerous studies have been published on the effect of car headlights when there is no road lighting. For instance, when the speed limit of a road is low or when a driver is driving with a low speed, drivers are able to stop within the range of car headlights and thus to avoid collisions, road lighting can be dimmed or kept at a dimmed level. Several studies focused on the visible distance when the driver only have low-beam car headlights during night-time driving on non-illuminated roads; these found that the range of vision during night depends on the speed of the car ${ }^{15,32,34,54)}$. These studies can imply where and when dimmed road lighting can be applied.

As described, the mean detection distances on an unlit road with only low-beam headlights for the large target ranged from $51 \mathrm{~m}$ to $122 \mathrm{~m}$, while for the small target, the mean detection distances ranged from 45 to $100 \mathrm{~m}^{20)}$. Considering $45 \mathrm{~m}$ and $51 \mathrm{~m}$ detection distances as a total stopping distance, safe approaching speed can be found via total stopping distance formula*3. Stopping distances for a range of design speeds can be seen in Figure 5 .

${ }^{* 3} S S D=0.278(v)(t)+0.039\left(\frac{v^{2}}{a}\right)$

Where SSD is required stopping sight distance $(\mathrm{m}), \mathrm{v}$ corresponds to the speed $(\mathrm{km} / \mathrm{h}), \mathrm{t}$ is perception reaction time $(\mathrm{s})$, typically $2.5 \mathrm{~s}$ for design, a represents deceleration rate $\left(\mathrm{m} / \mathrm{s}^{2}\right)$, for normal conditions, $3.4 \mathrm{~m} / \mathrm{s}^{2}$. 
The results indicate that for distances ranging from 45 to $51 \mathrm{~m}$ (least mean detection distances for both target and large target) meters the safe approaching speed is up to $50 \mathrm{~km} / \mathrm{h}$, meaning that the car can be stopped before $72 \mathrm{~m}$ of car headlights.

As mentioned, the effect of car headlights is reduced significantly at speeds over that $50 \mathrm{~km} / \mathrm{h}$ known as over-driving headlights. Therefore, road lights can be dimmed for speeds up to $50 \mathrm{~km} / \mathrm{h}$ (low speed, low road light). Accordingly, increased road lighting is only necessary above certain vehicle speeds. Another option that was also proposed by Boyce ${ }^{15)}$, is to introduce variable speed limits during day and night. Introducing lower speed limits on unlit or dimmed roads after dark, helps drivers not to overdrive their headlights. The technology detects both oncoming headlights and preceding taillights and reduces headlight intensity in the direction that can affect the other driver ${ }^{55)}$. Consequently, higher stopping or detection distance can be expected than when using only low beam headlights with speed of $48 \mathrm{~km} / \mathrm{h}(30 \mathrm{mph})$ when there is no glare from an oncoming cars. Road lighting practices can benefit from these vertical illumination to save energy without compromising traffic safety. To date, no studies have focused on the relationship between overdriving car headlights and road lighting. Therefore for speeds higher than $50 \mathrm{~km} / \mathrm{h}$ road lighting can be at the recommended level. Further research is needed to investigate the relationship between overdriving car headlights and road lighting.

Road lighting reduces the adverse effect of glare from oncoming traffic; therefore, the presence of road lighting is beneficial in motorised traffic. Since no significant differences were found in detection distances under different road lighting levels in the presence of glare from an oncoming car, it can be concluded that wherever there is oncoming traffic, the full road lighting level is likely to be favourable.

In addition, in high traffic volume, when the traffic is dense, driver attention is limited to the front car (limited sight distance); thus, low lighting levels can provide satisfactory vision. For example, an individual car at high speed might require higher lighting levels than a group of cars with low-speed due to the combined effect of road lighting and car headlights and stopping distance. Another solution for reducing road lighting level while increasing visibility distance for a low dense traffic is by reducing the speed limit after dark.

It is possible to dim road lighting when traffic density is high, and the roadway operates at near capacity and to increase lighting to the recommended level by CIE when the traffic density decreases. However, there is no research on the effect of dimmable road lighting on traffic safety at different traffic densities which requires further studies.

Similarly, under specific weather conditions, e.g., snow-covered or wet roads, the amount of luminance can be excessive ( 2 to 4 times higher) compared to the luminance required in normal condition ${ }^{4,19}$. From this perspective, full intensity lighting is not necessary. However, in specific adverse circumstances such as during precipitation, fog, etc., recommended road lighting level may be required. Table 4 below summarises the parameters that affect lighting class for CIE recommendation and provides a preliminary guideline of how such interaction of parameters should influence intelligent road lighting practices.

One problem with this approach is that it fails to take different types of roads into account. Therefore, the suggestions can be applied to straight roads (Figure 6a) and any changes on other road sections such as intersections, roundabouts, etc. (Figure 6b), should be studied. Figure 6 shows different route facilities.

This study, therefore, suggests three applications: Static, Semi-Dynamic and Dynamic intelligent road lighting.

Table 4 Parameters that affect lighting class for CIE recommendation and suggested reconsideration.

\begin{tabular}{lll}
\hline \multicolumn{1}{c}{ Parameters } & \multicolumn{1}{c}{ Options } & \multicolumn{1}{c}{ Lighting level } \\
\hline \multirow{2}{*}{ Presence of car } & No & Min light \\
& Yes & Detect speed \\
\hline \multirow{2}{*}{ Speed } & above $50 \mathrm{~km} / \mathrm{h}$ & At recommended level by CIE \\
& below $50 \mathrm{~km} / \mathrm{h}$ & Min light \\
\hline \multirow{2}{*}{ Traffic volume } & Very high (congested) & Min light \\
& High (low headways) & Min light \\
\hline \multirow{3}{*}{ Ambient luminance } & Low (high headways) & Detect speed \\
& dry (normal) & Detect car \\
& Wet & Min light \\
& Snow & Min light \\
& Adverse weather (i.e., for, during precipitation) & At recommended level by CIE \\
\hline
\end{tabular}



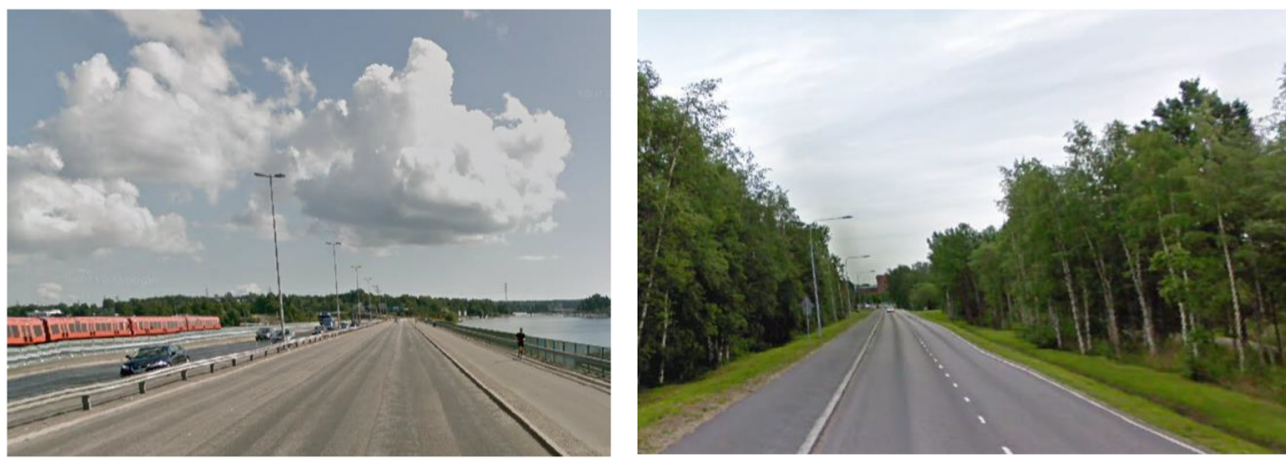

a) Straight stretch of road
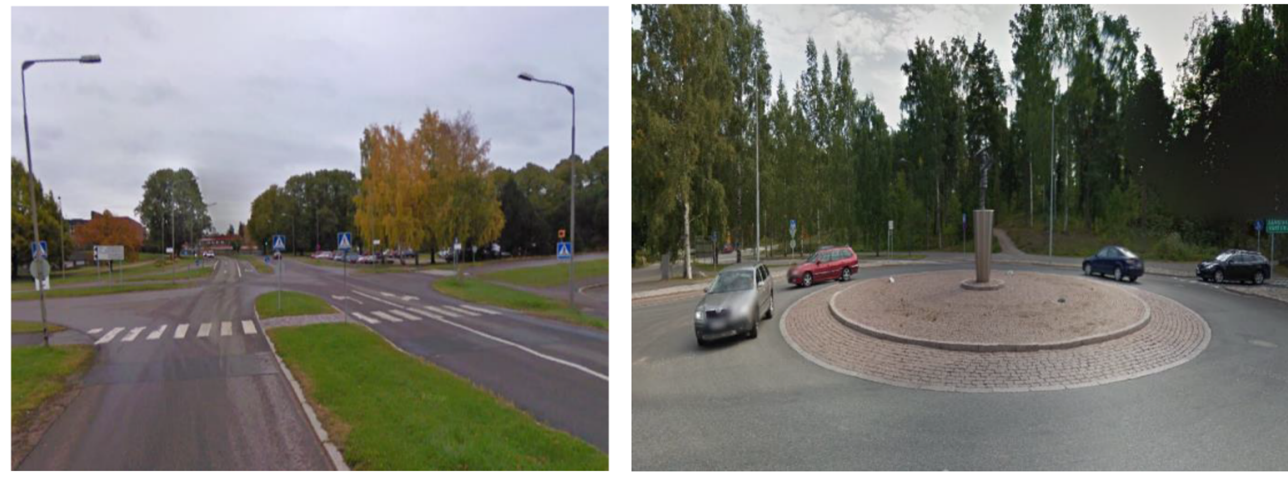

b) Different route facilities, junction, and roundabout

Figure 6 Different route facilities (Source: Google Maps).

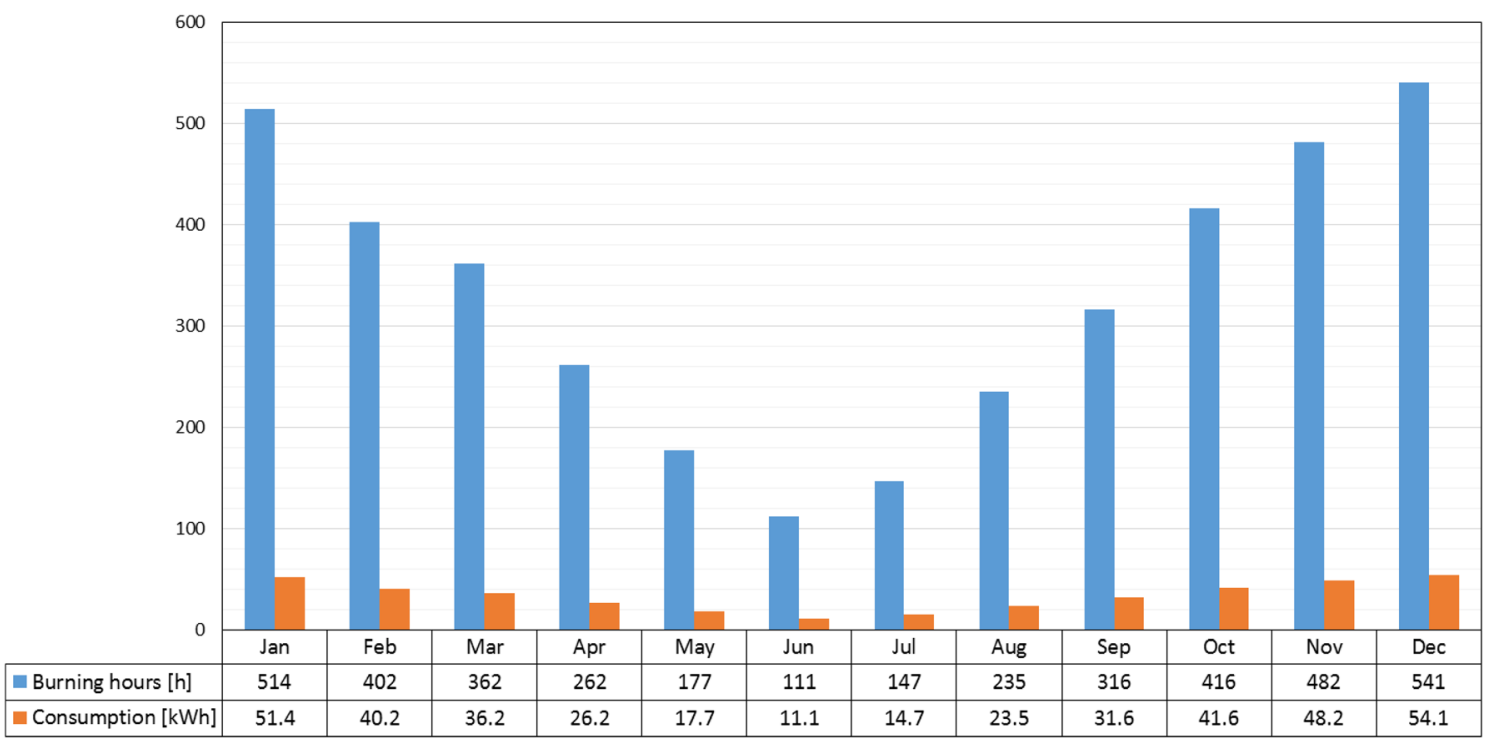

Figure 7 Monthly burning hours (h) and energy consumption (kWh) for one pole without dimming, Helsinki, Finland in 2014 (Ref: City of Helsinki).

\subsection{Static road lighting}

An easy approach to save energy without compromising safety is to have road lighting on all roads on the low lighting level and use the dynamic speed limit for day and night-time driving. The low-speed limit can result in short visibility distance that lay in low-beam headlight distribution. Also, the minimum road lighting level allows drivers to see the surrounding, traffic signs and reduce the effect of glare from oncoming traffic.

With regard to energy saving, introducing a static road lighting design, which does not reduce visibility performance, will significantly reduce energy usage. For example, in Finland, the length of light and dark time varies throughout the year. Figure 7 illustrates the monthly burning hours (h) and energy consumption $(\mathrm{kWh})$ of one pole without dimming in 2014. On 
one end of the spectrum, energy consumption in the summertime is the lowest because of the long duration of daylight; at the other, winter months have the highest energy consumption due to the short daylight hours, which balances the low energy consumption in summer.

On average in 2014, the annual burning hours of one luminaire were $3965 \mathrm{~h}$, with an energy consumption of $396.5 \mathrm{kWh}$. By reducing road lighting output to $20 \%$ $\left(\mathrm{L}_{\mathrm{ave}}=0.19 \mathrm{~cd} / \mathrm{m}^{2}\right)$ from the full the energy consumption can be $79.3 \mathrm{kWh} /$ year/luminaire, saving will be $317 \mathrm{kWh}$ /year/luminaire. The average price for energy (retail price) in 2016 was 8 cents/kWh consisted of market price, transfer prices and tax prices used in ${ }^{56-60)}$. Therefore, the total energy cost for one luminaire without dimming will be 31.72 euro/year, by reducing road lighting to $20 \%\left(\mathrm{~L}_{\mathrm{ave}}=0.19 \mathrm{~cd} / \mathrm{m}^{2}\right)$, from the full $\mathrm{road}$ lighting intensity $\left(\mathrm{L}_{\mathrm{ave}}=0.79 \mathrm{~cd} / \mathrm{m}^{2}\right)$, the cost will be 6.35 euro/luminaire/year, and savings for each luminaire will be 25.36 euro/luminaire/year.

To apply this concept, the lighting designer would select the lowest viable roadway traffic/pedestrian use levels and select light levels based on those, without large over-design factors. Working with the local authorities, the municipality could restrict speed limits and pedestrian use on these facilities where the intent is to use lower light levels.

\subsection{Semi-Dynamic road lighting level}

This approach attempts to predict what is most likely to happen. Therefore, to determine the appropriate level of light and apply this application, ambient light data and traffic volume data are needed. The data from the weather forecast can be used to predict road luminance measurements in different weather conditions. Alternatively, the system could use an ambient light sensor to reduce levels from the road lighting when there is high ambient light (from snow, etc.), Luminance of snowy and wet road surfaces can be 2 to 4 times $^{4,19)}$ higher than in dry conditions. In addition, time clocks can be used to dim lighting during hours of reduced usage. Traffic volume data can be found either by traffic volume detectors, or based on previously collected data, or data for similar roads in similar locations.

Energy and cost-saving in this application can vary depending on the duration of dimming and lighting technology. Two lighting technologies that can be used in this application are High-Pressure Sodium (HPS) or LED luminaires due to their ability to dim. There are several benefits associated with LED luminaires over HPS luminaires, excluding initial costs (i.e., purchase and installation costs). Some example benefits of LED over HPS luminaires are, higher luminous efficacy, higher lamp life in which dimming could also increase LEDs lifetime, instant ignition, more dimming range in which LEDs can be dimmed between 0-100\% while HPS lamps can be dimmed to roughly $50 \%{ }^{61,62)}$.

\subsection{Dynamic road lighting level}

This approach would require technology to dynamically, and in real-time, monitor control parameters as needed. In this approach, attention is mainly given to car lights because these are used whenever the car is in motion, regardless of whether the road is lit or not. Therefore, for a smooth lighting level change in this application, sensors that detect car movements, speeds, and headways would be necessary. Traffic data can be collected with inductive loops or cameras (possibly providing traffic data for each lane, and direction). Also, luminance meters would be required to check the road surface luminance. The resulting data would then be used to control the light level based on real-time demand $^{63)}$.

Similar to the semi-dynamic lighting level application, energy and cost-savings related to this application depends on the duration of dimming. LEDs are suitable technology for this application due to the instant capability to be frequently dimmed ${ }^{61,62)}$. Therefore, the lighting output can be adjusted in real-time based on real-time demand.

\section{Concluding remark}

In-depth analysis of current knowledge suggests that there are possibilities to control road lighting level based on demand. Road lighting level can be altered as parameters such as road surface condition, presence of car headlights, traffic volume, and car's speed changes throughout the night. Therefore, three practices to adjust road lighting level based on demand are suggested, static road lighting, semi-dynamic road lighting level, and dynamic road lighting level. The lighting control system can be adjusted based on available financial, technology and environmental constraints.

\section{Acknowledgments}

The first author is supported by the Aalto Energy Efficiency Research Programme (the "Light EnergyEfficient and Safe Traffic Environments" project). The authors would like to thank Tapio Luttinen, Iisakki Kosonen and Claudio Roncoli from Aalto University for their collaborations in this research.

\section{References}

(1) WHO: "The top 10 causes of death," 2018. [Online]. Available: http://www.who.int/mediacentre/ factsheets/fs310/en/

(2) CIE: Commission Internationale de l'Eclairage, "Road lighting as an accident countermeasure," in 
CIE. Publication No. 93.122, Vienna (Austria), 1992.

(3) Elvik, R.: Meta-analysis of evaluations of public lighting as accident countermeasure, Transp. Res. Rec., pp. 112-123 (1995). (TRR)

(4) Wanvik, P.: Effects of road lighting: An analysis based on Dutch accident statistics 1987-2006, Accid. Anal. Prev., 41-1, pp. 123-128 (2009).

(5) Elder, R. W., Shults, R. A., Sleet, D. A., Nichols, J. L., Thompson, R. S. and Rajab, W.: Effectiveness of mass media campaigns for reducing drinking and driving and alcohol-involved crashes: A systematic review, Am. J. Prev. Med., 27, pp. 57-65 (2004).

(6) Reis, A. D., Figlie, N. B. and Laranjeira, R.: Prevalence of substance use among trauma patients treated in a Brazilian emergency room, Rev. Bras. Psiquiatr., 28-3, pp. 191-195 (2006).

(7) McEvoy, S. and Stevenson, M.: "An exploration of the role of driver distraction in serious road crashes," 2007.

(8) Consiglio, W., Driscoll, P., Witte, M. and Berg, W. P.: Effect of cellular telephone conversations and other potential interference on reaction time in a braking response, Accid. Anal. Prev., 35-4, pp. 495-500 (2003).

(9) Horne, J. and Reyner, L.: Vehicle accidents related to sleep: A review, Occup. Environ. Med., 56-5, pp. 289-294 (1999).

(10) Garbarino, S., Lino, N., Beelke, M., De Carli, F. and Ferrillo, F.: The contributing role of sleepiness in highway vehicle accidents, Sleep, 24-2, pp. 201-206 (2001).

(11) Sallinen, M. and Hublin, C.: Fatigue-inducing factors in transportation operators, Rev. Hum. Factors Ergon., 10-1, pp. 138-173 (2015).

(12) Donnell, E. T., Porter, R. J. and Shankar, V. N.: A framework for estimating the safety effects of roadway lighting at intersections, Saf. Sci., 48-10, pp. 1436-1444 (2010).

(13) Bullough, J., Donnell, E. T. and Rea, M. S.: Roadway intersections, lighting and safety, International Municipal Signal Association, 51-5, pp. 32-35 (2013a). (IMSA)

(14) Bullough, J., Donnell, E. and Rea, M. S.: To illuminate or not to illuminate: Roadway lighting as it affects traffic safety at intersections, Journal of Accident Analysis and Prevention, 53, pp. 65-77 (2013b).

(15) Boyce, P. R.: Lighting for Driving: Roads, Vehicles, Signs, and Signals, New York: Taylor \& Francis Group, CRC Press, 2009.

(16) Waide, P. and Tanishima, S.: International Energy Agency (IEA), Light's labour lost: Policies for Energy-efficient Lighting Series: Energy efficiency policy profiles, 2006.

(17) Guo, L., Eloholma, M. and Halonen, L.: Lighting control strategies for telemanagement road lighting control systems, Journal of the Illuminationg Engineering Society of North America, 4-3, pp. 157-171 (2013).

(18) Black Sea Regional Energy Centre: “Intelligent road and street lighting in Europe. Report on small-scale test projects," 2007. [Online]. Available: http://www.greenpartnerships.eu/wp/wpcontent/uploads/Intelligent-Road-and-StreetLighting-in-Europe.pdf [Accessed 30 April 2017].

(19) Ekrias, A., Eloholma, M. and Halonen, L.: Analysis of road lighting quantity and quality in varying weather conditions, The Journal of the Illuminating Engineering Society, 4-2, pp. 89-98 (2007).

(20) Perel, M., Olson, P., Sivak, M. and Medlin, J.: "Motor vehicle forward lighting. SAE technical papers No. 830567," International Congress \& Exposition Detroit, Michigan, 1983.

(21) NHTSA (National Highway Traffic Safety Administration): "Night time glare and driving performance," 2007. [Online]. Available: https://www. nhtsa.gov/sites/nhtsa.dot.gov/files/glare_congressional_report.pdf [Accessed 10 November 2018].

(22) Bullough, J., and Rea M. S., "Visibility from vehicle headlamps and roadway lighting in urban, suburban and rural locations," SAE international, 2010.

(23) Akashi, Y., Dee, P., Chen, J., Van Derlofske, J. and Bullough, J.: "The interaction between fixed roadway lighting and vehicle forward lighting," Symposium: Darmstadt University of Technology, 2003.

(24) Bacelar, A.: The contribution of vehicle lights in urban and peripheral urban environments, Light. Res. Technol., 36-1, pp. 69-78 (2004).

(25) Skinner, N. P. and Bullough, J.: "Influence of intelligent vehicle headlamps on pedestrian visibility in roundabouts," in 9th International Symposium on Automotive Lighting (pp. 1047-1060), Darmstadt, Germany, September 26-28, Munchen, Germany: Herbert Utz Verlag, 2011.

(26) Bullough, J. and Skinner, N.: Vehicle lighting and modern roundabouts: Implications for pedestrian safety, SAE Int. J. Passeng. Cars Mech. Syst., 5-1, pp. 195-198 (2012).

(27) Bozorg Chenani, S., Vaaja, M. T., Kurkela, M., Kosonen, I. and Luttinen, T.: Target detection distance under different road lighting intensities, Journal of European Transport Research Review, 9, pp. 9-17 (2017).

(28) Bozorg, S., Tetri, E., Kosonen, I. and Luttinen, T.: The Effect of dimmed road lighting and car headlights on visibility in varying road surface conditions, The Journal of the Illuminating Engineering Society, 14-4, pp. 1-15 (2018).

(29) Sullivan, J., Adachi, G., Mefford, M. and Flannagan, M.: High-beam headlamp usage on unlighted ru- 
ral roadways, Light. Res. Technol., 36-1, pp. 59-65 (2004).

(30) Bullough, J., "High-Beam Intensity, Visual Performance and Safety-Related Impacts," A Transportation Lighting Alliance Report. No. TLA 2015-01, 2015.

(31) Ekrias, A., Guo, L., Eloholma, M. and Halonen, L.: Intelligent road lighting control in varying weather conditions, Journal of Light and Engineering, 17-1, pp. 72-78 (2008).

(32) Leibowitz, H. W., Owens, D. A. and Tyrrell, R. A.: The assured clear distance ahead rule: Implications for nighttime traffic safety and the law, Journal of Accident Analysis and Prevention, 30-1, pp. 93-99 (1998).

(33) Van Bommel, W. N.: Road lighting: Fundamentals, technology, and application, Switzerland: Springer, 2015.

(34) Johansson, G. and Rumar, K.: Visible distance and safe approach speeds for night driving, Ergonomics, 11-3, pp. 275-282 (1968).

(35) Elvik, R. and Vaa, T.: The Handbook of the Road Safety Measures Second Edition, Oxford: Elsevier Ltd. ISBN: 978-1-84855-250-0, 2009.

(36) Schreuder, D. A.: Road lighting for safety, Thomas Telford, 1998

(37) Bacelar, A.: The influence of dimming in road lighting on the visibility of drivers, Journal of Lighting and Vision Environment, 29-1, pp. 44-49, 2005.

(38) Oya, H., Mitsuhashi, K. and Ando, K.: "A study on visibility at the fusion of road lighting and headlamps," in 79th Annual Transportation Research Board Meeting, January 2000, Washington, DC., 2000.

(39) Bozorg Chenani, S., Maksimainen, M., Tetri, E., Kosonen, I. and Luttinen, T.: The effect of dimmable road lighting: A comparison of measured and perceived visibility, Journal of Transportation Research Part F: Traffic Psychology and Behaviour, 43, pp. 141-156 (2016).

(40) Rea, M. S. and Ouellette, M. J.: Relative visual performance: A basis for application, Light. Res. Technol., 23-3, pp. 135-144 (1991).

(41) Bullough, J. and Radetsky, L. C.: "Sustainable Roadway Lighting Seminar, 14-28," in New York State Energy Research and Development Authority, Albany, NY, 2014.

(42) Gibbons, R.: Guo, F. Medina, A. Terry, T. Du, J. Lutkevich, P. Li Q., "Design criteria for adaptive roadway lighting," Report No. FHWA-HRT-14-051, Washington, D. C., 2014.

(43) Sivak, M., Schoettle, B., Mindoa, T. and Flannagan, M. J.: "Blue content of LED headlamps and discomfort glare," Report number UMTRI-2005-2, University of Michigan Transportation Institute, 2005.
(44) Skinner, N., Bullough, J. and Smith, A.: "Survey of the present state of vehicle headlamp aim (10-1283)," in TRB 2010 Annual Meeting, 2010.

(45) Bullough, J., Van Derlofske, J., Dee, P., Chen, J. and Akashi, Y.: An investigation of headlamp glare: Intensity, spectrum and size, Report No. DOT HS, 809, p. 672 (2003).

(46) Monsere, C. M., Yin, T. and Wolde, M.: "Understanding the safety effects of roadway illumination reductions," in Civil and Environmental Engineering Faculaty publications and presentations. 76, 2007.

(47) Steinbach, R., Perkins, C., Tompson, L., Johnson, S., Armstrong, B., Green, J., Grundy, C., Wilkinson, P. and Edwards, P.: The effect of reduced street lighting on road casualties and crime in England and Wales: Controlled interrupted time series analysis, J. Epidemiol. Community Health, 69-11, pp. 1118-1124 (2015).

(48) Tien, J. M. and O’Donnell, V.: V., A. I. Barnett and P. B. Mirchandani, "Street Lighting Projects: National Evaluation Program,” Phase I Final Report. Rockville, MD: National Institute of Justice, 1977.

(49) Rea, M. S., Bullough, J. D., Fay, C. R., Brons, J. A., Van Derlofske, J. and Donnell, E. T.: "Review of the Safety Benefits and Other Effects of Roadway Lighting," Washington, D. C., 2009.

(50) CIE: Commission Internationale de l'Eclairage, "Lighting of roads for motor and pedestrian traffic," in CIE Report No. 115-2010, Vienna (Austria), 2010.

(51) Europe, E-street, "Intelligent road and street lighting in Europe," 2008. [Online]. Available: https:// ec.europa.eu/energy/intelligent/projects/sites/ iee-projects/files/projects/documents/e-street_e_ street_publishable_report_en.pdf

(52) Guo, L., Eloholma, M. and Halonen, L.: Luminance monitoring and optimisation of luminance metering in intelligent road lighting control systems, Journal of Ingineria Iluminatului, 9, pp. 24-40 (2007).

(53) Bozorg, S.: "The effect of different road lighting levels on drivers' visual performance under various conditions," 2019. [Online]. Available: online available at https://aaltodoc.aalto.fi/ handle/123456789/39369

(54) Janoff, M. S., Staplin, L. and Arens, J.: The potential for reduced lighting on roadways, Journal of Public Roads, 50-2, pp. 33-42 (1986).

(55) Bullough. J., Skinner, N., Plummer, T., "Adaptive driving beam headlights: Visibility, glare and measurement considerations," Technical Report TLA2016-01, June 2016, 2016.

(56) AASHTO (American Association of State Highway and Transportation): "A policy on geometric 
design of highway and streets," Washington, D.C., 1984.

(57) Vand, B., Martin, K., Jokisalo, J., Kosonen, R. and Hast, A.: Demand response potential of district heating and ventilation in an educational office building, Science and Technology for the Built Environment, 26-3, pp. 304-319 (2020).

(58) Vand, B., Hast, A., Bozorg, S., Li, Z., Syri, S. and Deng, S.: Consumers' attitudes to support green energy: A case study in shanghai, Energies, 12-12, p. 2379 (2019).

(59) Alimohammadisagvand, B.: "Influence of Demand Response Actions on Thermal Comfort and Electricity Cost for Residential Houses," Doctoral Dissertation. Aalto University, School of Engineering, Available online: https://aaltodoc. aalto.fi/bitstream/handle/123456789/33143/ isbn9789526081120.pdf? sequence $=1 \&$ is Allowed $=y$, 2018

(60) Alimohammadisagvand, B., Jokisalo, J. and Sirén, $\mathrm{K}$.: "The potential of predictive control in minimising the electricity cost in a heat-pump heated residential house," in In Proceedings of the 3rd IBPSA-England Conference BSO 2016, Great North Museum, Newcastle, 12th-14th September 2016.

(61) Tetri, E., Bozorg Chenani, S., Räsänen, R.-S., Baumgartner, H., Vaaja, M., Sierla, S., Tähkämö, L., Virtanen, J.-P., Kurkela, M., Ikonen, E., Halonen, L., Hyyppä, H. and Kosonen, I.: Tutorial: Road lighting for efficient and safe traffic environments, LEUKOS The Journal of the Illuminating Engineering Society of North America, 13-4, pp. 223241 (2017).

(62) Tetri, E., Bozorg Chenani, S. and Rasanen, R.: Advancement in road lighting, Journal of Light \& Engineering, 26-2, pp. 99-109 (2018).

(63) Guo, L:: "Intelligent road lighting control systemsexperiences, measurements, and lighting control strategies,” Espoo, Finland, 2008.

Part of this work was presented in the corresponding author's, Sanaz Bozorg, doctoral dissertation, August 2019, Espoo, Finland. 